\title{
Impact of COVID-19 pandemic on the clinical activities related to arrhythmias and electrophysiology in Italy: results of a survey promoted by AIAC (Italian Association of Arrhythmology and Cardiac Pacing)
}

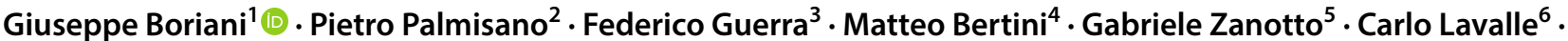 \\ Pasquale Notarstefano ${ }^{7}$. Michele Accogli ${ }^{2}$. Giovanni Bisignani ${ }^{8}$. Giovanni Battista Forleo ${ }^{9} \cdot$ Maurizio Landolina $^{10}$. \\ Antonio D'Onofrio ${ }^{11} \cdot$ Renato Ricci ${ }^{12} \cdot$ Roberto De Ponti $^{13}$ on behalf of AIAC Ricerca Network Investigators
}

Received: 4 July 2020 / Accepted: 21 August 2020 / Published online: 5 September 2020

(C) Società Italiana di Medicina Interna (SIMI) 2020

\begin{abstract}
COVID-19 outbreak had a major impact on the organization of care in Italy, and a survey to evaluate provision of for arrhythmia during COVID-19 outbreak (March-April 2020) was launched. A total of 104 physicians from 84 Italian arrhythmia centres took part in the survey. The vast majority of participating centres (95.2\%) reported a significant reduction in the number of elective pacemaker implantations during the outbreak period compared to the corresponding two months of year 2019 (50.0\% of centres reported a reduction of $>50 \%)$. Similarly, $92.9 \%$ of participating centres reported a significant reduction in the number of implantable cardioverter-defibrillator (ICD) implantations for primary prevention, and $72.6 \%$ a significant reduction of ICD implantations for secondary prevention ( $>50 \%$ in 65.5 and $44.0 \%$ of the centres, respectively). The majority of participating centres (77.4\%) reported a significant reduction in the number of elective ablations $(>50 \%$ in $65.5 \%$ of the centres). Also the interventional procedures performed in an emergency setting, as well as acute management of atrial fibrillation had a marked reduction, thus leading to the conclusion that the impact of COVID-19 was disrupting the entire organization of health care, with a massive impact on the activities and procedures related to arrhythmia management in Italy.
\end{abstract}

Keywords Ablation · Arrhythmia · Atrial fibrillation · Emergency · Implantable cardioverter defibrillators · Pacemakers · Remote monitoring $\cdot$ COVID-19

\section{Introduction}

The World Health Organization declared COVID-19 a pandemic on March 11, 2020 (1) and Italy was the first European country that had to take urgent decisions for limiting the transmission in the population of Sars-Cov-2 [1]. On March 8th, Italy became the second most affected country in

The list of Investigators participating to AIAC Ricerca Network is reported in the Acknowledgements section.

Electronic supplementary material The online version of this article (https://doi.org/10.1007/s11739-020-02487-w) contains supplementary material, which is available to authorized users.

Giuseppe Boriani

giuseppe.boriani@unimore.it

Extended author information available on the last page of the article the world after China, and specific rules for restricting social contacts in the whole country were applied by the Italian Government in March 2020 [2]. At the end of June 2020 the total number of subjects found affected by COVID-19 in Italy was reported to be around 240000 with more than 34,000 deaths [3].

The COVID-19 outbreak had a devastating and massive impact on the organization of social activities, as well as a disruptive impact on the organization of care in Italy, with a dramatic reduction in traditional contacts for ensuring care to non COVID-19 diseases [4]. As a matter of fact, hospital admissions for acute myocardial infarction were significantly reduced during the early phase of COVID-19 pandemic across Italy, with a parallel increase in fatality and complication rates [5]. Moreover, a 52\% increase in the occurrence of out of hospital cardiac arrests was documented in some Provinces from Lombardy in the first 2 months of the 
pandemic, and this increase was associated with worse in hospital outcomes [6].

Within this complex scenario, corresponding to a profound re-arrangement of health care system organization in Italy, no data are available on the different aspects of care in the field of arrhythmia and electrophysiology, either with regard to the period of lockdown or with regard to the so called "Phase 2" (post-COVID-19 recovery phase) that started on May 4, 2020 targeted to a re-organization of all the activities, including health care, after the period of massive emergency. The Italian Association of Arrhythmology and Cardiac Pacing (AIAC) launched a survey among its members in order to report the situation of cardiac care for arrhythmia in these particular phases.

\section{Materials and methods}

From April 24 to May 30, 2020 a survey endorsed by the AIAC was published on the official AIAC website (https:// aiac.it/). The survey was open to physicians operating in all Italian centres involved in arrhythmia care. Participation in the survey was voluntary. The questionnaire could be completed by more than one physician from the same centre.

The questionnaire consisted of 18 questions: five of them focused on the characteristics of the participating centre (i.e. involvement of the centres and of the physicians in the management of suspected and confirmed patients with COVID19, volume of annual CIEDs implantations and ablation procedures); seven of them focused on the impact of COVID-19 pandemic on the number of CIED implantations and ablation procedures performed in both elective and emergency settings, and on the number of cases of acute pharmacological and non-pharmacological treatment of atrial fibrillation (AF) in emergency setting; two of them focused on the impact of COVID-19 pandemic on the management of remote monitoring (RM) of CIEDs; the remaining four were focused on the possible organizational strategies for post-COVID-19 recovery phase. Seventeen of the 18 questions were multiple-choice questions (see online Supplementary material for details).

\section{Statistical analysis}

Descriptive statistics were reported as means for normally distributed continuous variables. Continuous variables with skewed distribution were reported as medians with 25-75th percentiles. Categorical data were expressed as percentages, reported in contingency tables, and compared by means of $\chi^{2}$ test or Fisher's exact test, as appropriate. $p$ values $<0.05$ were considered statistically significant.

\section{Results}

\section{Participating centres}

A total of 104 physicians from 84 Italian arrhythmia centres took part in the survey. For 15 centres, more than one physician responded to the survey (mean; 2; range 2-4). A complete list of participating centres is reported in Appendix. The centres which participated in the survey accounted for $22.6 \%$ of all 372 arrhythmia centres operating in Italy in 2019 [7]. The participating centres displayed a wide geographical distribution (Fig. 1b): a mean of three centres per region (range: $0-13$; interquartile range: $1-7$ ) responded. In six regions there were five or more participating centres. The response rate was similar in Northern, Central and Southern Italy $(21.6,30.7$, and $18.0 \%$ of all operating centres, respectively, $p=0.089)$. After dividing the Italian regions into four groups, according to incidence of COVID-19 cases (confirmed cases $<1.0$, from 1.1 to 3.0 , from 3.1 to 5.0 , and $>5.0$ per 1000 populations, Fig. 1a) (3), the response rate was similar in the regions with higher incidence of COVID-19 cases (confirmed cases $>5$ per 1000 population, $n=6$ ) compared to other regions $(n=14)(22.9$ vs. $22.4 \% ; p=0.921)$.

Many participating centres $(29.8 \%)$ had three operators, $4.8 \%$ had only one operator, and $6.0 \%>6$ operators (Fig. 1c). Fifty-nine of 84 participating centres (70.2\%) were located in hospitals designated to treat patients with COVID-19. Of these, 43 (72.9\%) reported that during COVID-19 pandemic at least one operator (median: 1; range: 1-12) was directly involved in the management of patients with COVID-19. In these centres a mean of 71.6\% of operators was involved in assistance to patients with COVID-19 and in 21 centres (49\% of those involved in the care of patients with COVID-19), all the operators of the electrophysiology team were involved in assistance to patients with COVID-19.

The majority of participating centres $(54.8 \%)$ had implanted from 200 to 500 CIEDs during 2019; 21.4\% had implanted from 100 to 200 CIEDs, and the remaining $23.8 \%<100$ or $>500$ (Fig. 1d). In $34.5 \%$ of centres, $<50$ ablation procedures had been performed during 2019; $28.6 \%$ had been performed from 100 to 200 ablation procedures; $20.2 \%$ had been performed $>200$ ablation procedures (Fig. 1e).

\section{Impact of COVID-19 pandemic on the activity of participating centres}

Procedures performed in elective setting The vast majority of participating centres $(95.2 \%)$ reported a 


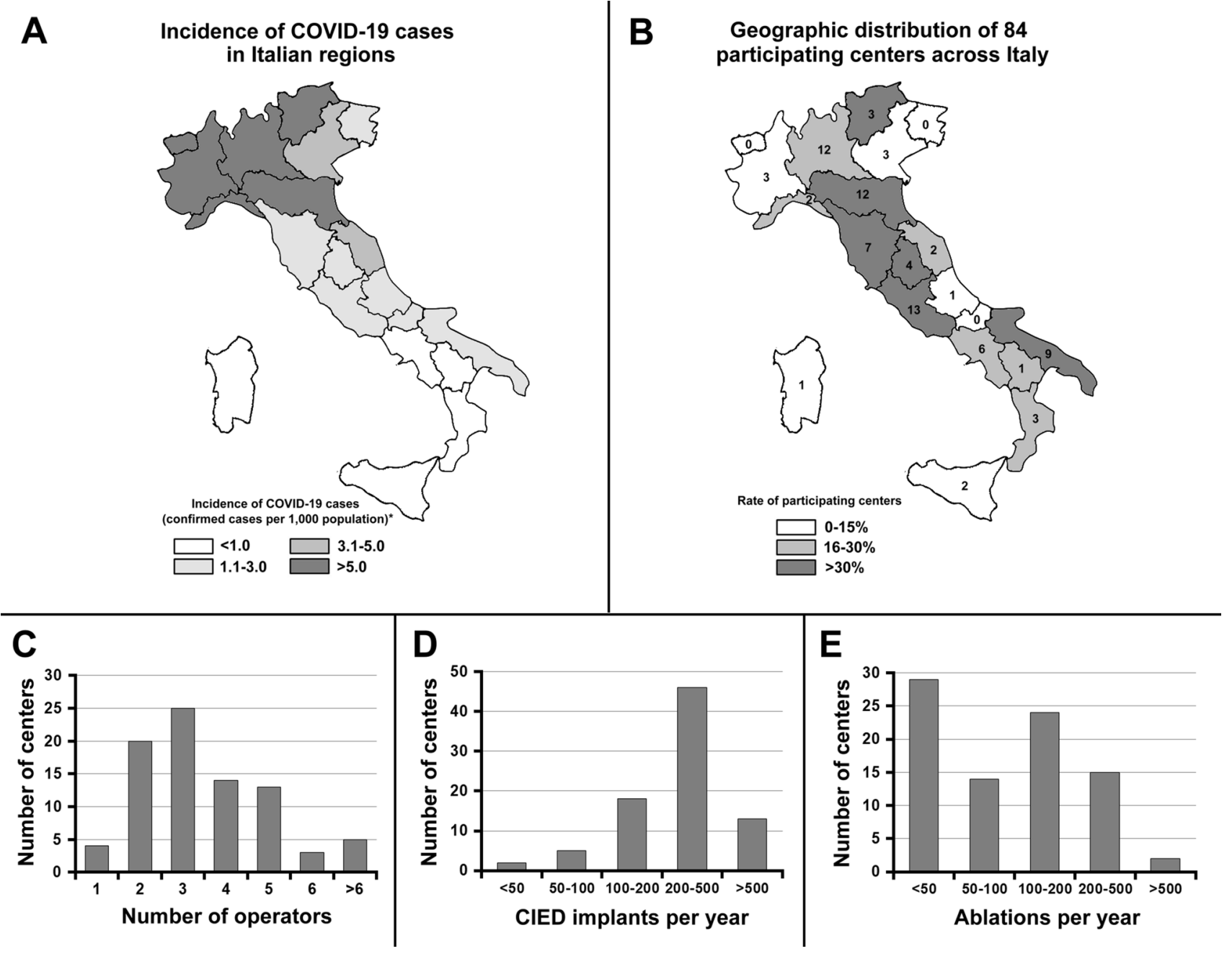

Fig. 1 Incidence of COVID-19 cases in Italian regions (a). Geographic distribution of the centres that responded to the survey across Italy (b). Number of operators per centre (c). CIED implantation vol-

significant reduction in the number of elective pacemaker (PM) implantations procedures during the two months March-April 2020 compared to the corresponding two months (March-April) of year 2019. Specifically, 50.0\% of centres reported a reduction of $>50 \%$. Only $4.8 \%$ of centres reported no significant variations (Fig. 2a). Similarly, $92.9 \%$ of participating centres reported a significant reduction in the number of implantable cardioverter-defibrillator (ICD) implantations for primary prevention in the same period. The majority of these $(65.5 \%)$ reported a reduction $>50 \%$. Only $7.1 \%$ of centres reported no significant variations (Fig. 2b). COVID-19 pandemic seemed to have an impact also on the number of ICD implantations for secondary prevention; in fact, $72.6 \%$ of centres reported a significant reduction (of $>50 \%$ in $44.0 \%$ of centres), while $27.4 \%$ reported no significant variations $(\mathrm{p}<0.001$ compared to ICD implantations for primary ume of participating centres (d). Ablation procedures volume of participating centres (e). *Data from Italian Civil Protection Department [3]. CIED cardiac implantable electronic device

prevention, Fig. 2b). No significant difference was found in the answers between the centres located in regions with higher incidence of COVID-19 cases and the other ones (Figure S1, panel A-C).

The majority of participating centres $(77.4 \%)$ reported a significant reduction in the number of elective ablations performed during the two months March-April 2020 compared to the 2 months March-April 2019 (reduction of $>50 \%$ in $65.5 \%$ of the centres); $22.6 \%$ reported no significant variations (Fig. 2c). The impact of the pandemic on the number of elective ablations performed was greater in the regions with higher incidence of COVID-19 cases where there was a significantly higher rate of the centres that reported a reduction in the number of procedures of $>50 \%$ ( 81.3 vs. $55.8 \%$; $p=0.017)$, and a significantly lower rate of the centres that reported no significant variations $(9.4$ vs. $30.8 \% ; p=0.023$ ) compared to other centres (Figure S1, panel D). 


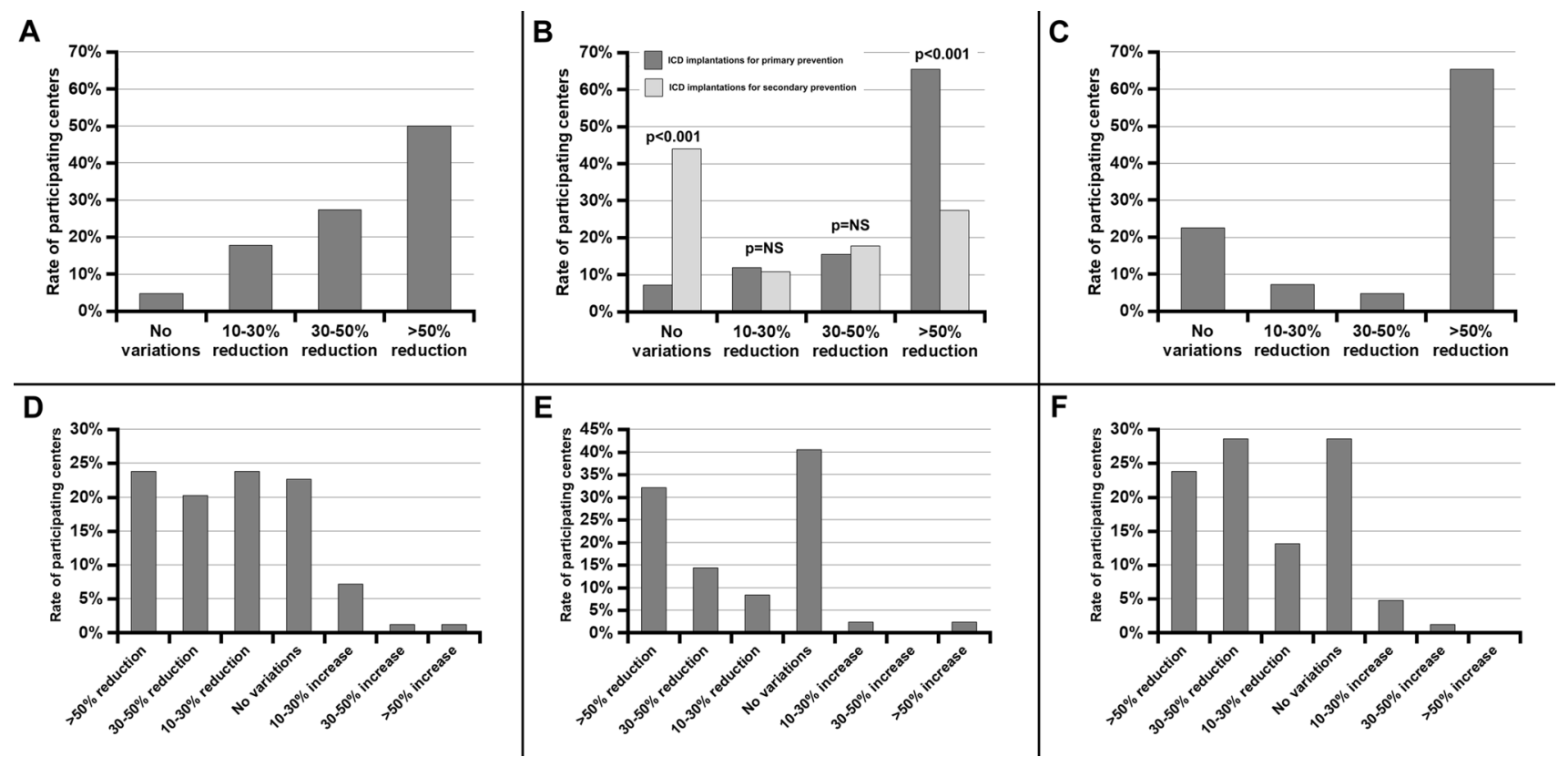

Fig. 2 Variations in the number of procedures reported by participating centres during the two months March-April 2020 compared to two months March-April 2019: elective pacemaker implantations (a); elective ICD implantations for primary prevention and for secondary prevention (b); elective ablations (c); CIEDs implantations in

During COVID-19 pandemic, the participating centres globally reported a mean reduction in the number of elective PM implantations, ICD implantations for primary prevention, ICD implantations for secondary preventions, and elective ablations of 52.0, 57.7, 40.9, and $52.4 \%$, respectively.

Procedures performed in emergency setting The majority of participating centres $(70.0 \%)$ reported a significant reduction in the number of CIED implantation procedures performed in emergency setting (including temporary and definitive PM implantations for severe, life-threatening bradyarrhythmias, and ICD implantations for secondary prevention) during COVID-19 pandemic compared to the same period of the previous year; $22.6 \%$ of centres reported no significant variations; $10.0 \%$ reported a significant increase (of $10-30 \%$ in most cases, Fig. 2d).

About half of the participating centres (54.8\%) reported a significant reduction in the number of ablation procedures performed in emergency setting (including urgent ablation of electrical storm, or of refractory ventricular or supraventricular tachycardias) during COVID-19 pandemic compared to the same period of the previous year (of $>50 \%$ in $32.1 \%$ of the centres); $40.5 \%$ reported no significant variations; only $4.8 \%$ reported a significant increase (Fig. 2e).

No significant difference was found in the answers between the centres located in regions with higher incidence of COVID-19 cases and the other ones (Figure S2, panel A and $\mathrm{B})$. emergency setting (d); ablations performed in emergency setting (e); cases requiring acute treatment of $\mathrm{AF}$ in emergency setting (f). $A F$ atrial fibrillation, CIEDs cardiac implantable electronic devices, $I C D$ implantable cardioverter-defibrillator

The majority of participating centres (65.5\%) reported a significant reduction of cases of acute pharmacological and non-pharmacological treatment of AF in emergency setting (including pharmacological rate or rhythm control, and urgent electrical cardioversion); $28.6 \%$ reported no significant variations; only $6.0 \%$ reported a significant increase (Fig. 2f). In the regions with higher incidence of COVID-19 cases a significantly higher rate of centres reported a reduction of $>50 \%$ in the number of cases of acute AF treatment in emergency setting compared to other regions (43.8 vs. $11.5 \% ; p<0.001$; Figure S2, panel C).

During COVID-19 pandemic, the participating centres globally reported a mean reduction in the number of urgent CIEDs implantations, urgent ablations, and in the number of cases requiring acute treatment of AF in emergency setting of $27.9,29.2$, and $30.5 \%$, respectively.

Based on the reported procedure volumes, we estimated that, during the two months March-April 2020 in the 84 centres that participated in the survey, globally about 2200 fewer CIEDs had been implanted and about 960 fewer ablations had been performed (in both elective and emergency settings) compared to the same period of the previous year.

Remote monitoring of CIEDs Eighty-one of 84 participating centres (96.4\%) used remote monitoring (RM) for the follow-up of patients with CIEDs. Almost half of these centres $(48.8 \%)$ reported no significant variations in the number of patients followed by RM during the two months that we 


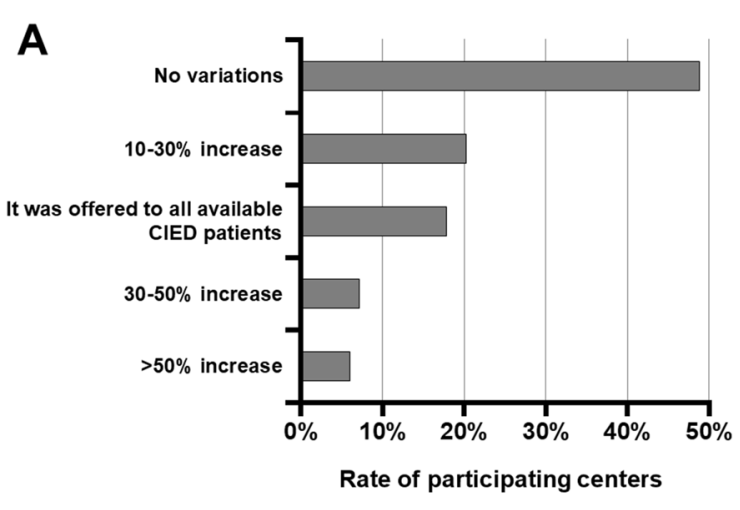

Fig. 3 Variations in the number of CIED patients followed by remote monitoring during the two months March-April 2020 compared to 2 months March-April 2019 (a). Management of in-office evaluation in

analysed (March-April 2020), while 33.3\% reported a significant increase; $17.9 \%$ declared to offer RM to all available CIED patients (Fig. 3a). About half of the centres (53.6\%) indicated that during COVID-19 pandemic performed inoffice evaluation of CIED patients followed by RM only in case of alerts triggered by device/lead malfunction or by clinical events; $21.4 \%$ performed in-office evaluation only in case of alerts related to device/lead malfunction; finally, $21.4 \%$ declared that during the pandemic no in-office evaluation was performed (Fig. 3b

\section{Strategies and perspectives for the post-COVID-19 recovery phase}

The following results refer to the whole group of 104 physicians who responded to the questionnaire. The majority of the interviewed physicians $(56.7 \%)$ considered, as main strategy for the post-COVID-19 recovery phase, the adoption of new organizational structures for patient admission in order to minimize the risk of infection. Besides,

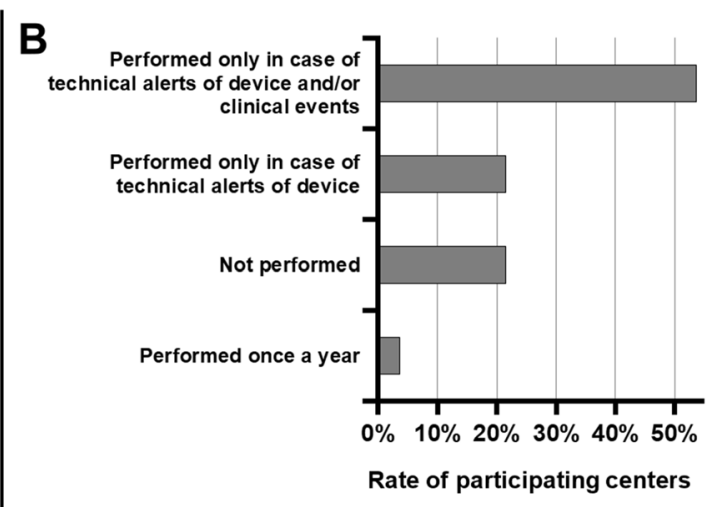

CIED patients followed by remote monitoring during COVID-19 pandemic (b). CIED cardiac implantable electronic device

$33.7 \%$ of respondents considered as main strategy the implementation of short-stay hospitalization for patients undergoing elective procedures (i.e. day-case admission or ordinary admission with a single night stay). Finally, $20.2 \%$ of respondents considered as the main challenge for post-COVID-19 phase to overcome the distrust of patients to go to the hospital.

For the majority of the interviewed physicians (73.1\%) the procedures that could be performed under day-case admission were CIEDs replacements, followed by supraventricular tachycardias (SVTs) ablations (22.1\%) and by elective PM implantations (16.3\%, Fig. 4a). Instead, the procedures, that could be performed under ordinary admission with a single night stay, were elective PM implantations for $60.6 \%$ of respondents, elective ICD implantations for $56.7 \%$, SVTs ablations for $39.4 \%$, and CIEDs replacements for $32.7 \%$ (Fig. 4b).

Concerning the time needed to return to pre-COVID procedure volumes, about a third of respondents (32.7\%) thought that it will take at least 6 months; $26.9 \%$ that it
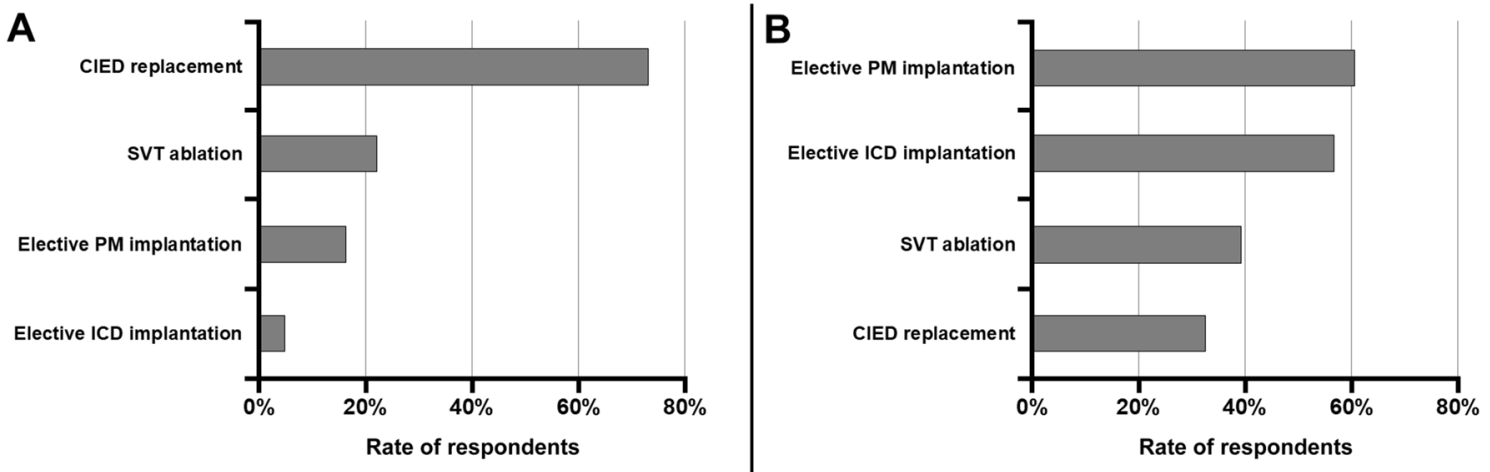

Fig. 4 Procedures that could be performed under day-case admission (a), and under ordinary admission with a single night stay (b). CIED cardiac implantable electronic device, $I C D$ implantable cardioverter-defibrillator, $P M$ pacemaker, $S V T$ supraventricular tachycardia 
will take from 1 to 2 years; $12.5 \%$ thought that the preCOVID-19 procedure volumes will be achieved within 3 months.

\section{Discussion}

The present survey highlights that the outbreak of COVID19 pandemic had a disrupting impact on health care organization that profoundly affected the organization of care in the Hospitals and the Cardiology Divisions of many areas, specifically in Northern Italy, with an important impact on the activities of the teams involved in management of arrhythmias and electrophysiology. Indeed,

around $70 \%$ of centres that participated to this survey were located in hospitals directly involved in treatment of patients with COVID-19 and around 73\% reported that during the pandemic at least one physician of the arrhythmia team was directly involved in the management of patients with COVID-19. The extraordinary consequences of the pandemic are even more evident by considering that in $49 \%$ of the centres involved in management of COVID-19 all the operators of the electrophysiology team were involved in tackling the emergency situation.

The elective procedures related to device implants had a very important reduction in March-April 2020 as compared to the same months of the previous year, with the majority, or even the large majority of centres reporting a greater than 50\% reduction in the number of elective PMs or of ICDs implanted in primary prevention of sudden cardiac death. The indication to limit hospital admissions to emergencies or, anyway, to non-deferrable procedures, combined with the fear of patients to be infected in the hospital are all factors that can explain this phenomenon whose impact on future events is unpredictable. The reduction in ICD implants for secondary prevention was less impressive, but these data should be interpreted in a larger perspective, taking into account the increase in out of hospital cardiac arrests observed during the COVID-19 outbreak [6]. It is noteworthy that no significant difference was found in the analysis on device implants between the centres located in regions with higher incidence of COVID-19 cases and the other ones, suggesting that the impact of the pandemic on patient behaviours and organization of care was, in general, independent on the peaks of COVID-19 epidemiological pressure. It is unknown whether the reduction in elective implants for prophylactic ICDs will imply in the future a relative increase in malignant ventricular tachyarrhythmias or cardiac arrests, leading to a rebound increase in ICDs implanted for secondary prevention.

Ablation of AF is currently one of the main activities of Italian electrophysiology centres, and is performed with different approaches and techniques both in patients with no underlying heart disease and in selected patients with heart failure [7-11]. In the present survey around $77 \%$ of the centres reported a significant reduction in the number of elective ablations performed in March-April 2020 compared to the previous years, but with some differences related to areas with higher incidence of COVID-19 cases. The elective nature of $\mathrm{AF}$ ablation procedures and the re-organization of care related to COVID-19, that obliged many centres to cancel elective procedures may explain the heterogeneity of this finding.

Also the electrophysiological procedures and the interventions performed in an emergency setting were markedly reduced during the observation period. In interpreting these findings, it should be considered that the COVID19 outbreak markedly changed the pattern of Emergency Departments (EDs) referral in Italy, with figures up to a $50 \%$ reduction accesses to hospitals and EDs unrelated to COVID-19 [12, 13]. A reduction up to 50\% in urgent pacemaker implants for severe bradyarrhythmias was previously reported, in agreement with our national survey, by analysis performed on a single hospital basis or on a regional basis $[14,15]$. The reduction in urgent pacemaker implants may imply a lack of prevention for the potential harmful consequences of bradyarrhythmias and, indeed, a relative increase in the proportion of patients presenting with syncope due to bradyarrhythmias was already observed [15]. It is possible that this trend will increase also in the post-lockdown phase and it will be interesting to analyse if it will lead to a rebound in pacemaker implants.

In recent years RM of implanted devices has been implemented in clinical practice in a substantial proportion of Italian centres, despite the problems linked to lack of reimbursement or lack of official general plans for large-scale implementation [16-19]. As compared to patient monitoring with external devices, the use of remote monitoring with implanted devices offers the advantage of an easy implementation, simply requiring patient and caregiver's education coupled with availability of dedicated transmitters. Therefore, COVID-19 offered a great chance to enhance implementation of RM among patients with implanted devices [20], although with a variable extent from centre to centre. As a matter of fact, more than $50 \%$ of the centres participating to this survey reported some increase in the use of RM for the follow-up of their patients. However, the extent of RM implementation as a consequence of the limitations of COVID-19 lockdown actually ranged from an increase in the range of $10-30 \%$ of assisted patients to more than $50 \%$ or even (in around $18 \%$ of centres) to a complete shift to a strategy based on offering RM to all available CIED patients. Although it is clear that the pressure of the limitations due to COVID-19 lockdown offered a great opportunity for a larger implementation of RM, overcoming a series of bureaucratic and administrative barriers, it emerges a 
substantial heterogeneity in the extent of implementation of RM, that should be object of future re-assessments. The very drastic limitations linked to the period of massive pressure of CIVID-19 are highlighted by the relatively important proportion of centres (one in five) reporting that during the pandemic no in-office evaluations were performed. Currently remote programming of implanted devices is not allowed, in view of safety concerns, so it remains crucial the adoption of specific recommendations for device programming according to patient profile, thus minimizing troubleshooting during follow up [21, 22].

In the specific context of COVID-19 lockdown the potential advantages of RM should not be limited to device checks. As known, RM can be used with the purpose of remote device check or for monitoring patients' status (heart rhythm, fluid overload, right ventricular pressure, oximetry, etc.), thus with a shift from strictly device-centred follow-up to perspectives centred on the patient (and patient-device interactions) [23-28]. The organization of disease management of heart failure, though RM in patients with implanted devices is complex, requires an interplay between the competence on devices and heart failure management and, therefore, should be object of promotion for the post-COVID-19 recovery phase. The assessment of quality of care delivered through RM [29], with appropriate involvement of the patients and the caregivers [30], will become of primary importance for outcome improvement. Anyway, as stressed in official documents of the major international associations in the field of arrhythmia management, the crisis precipitated by the pandemic has surely catalysed the adoption of RM across many specialties and heart rhythm professionals are in the front line for full adoption of this technological and clinical advancement even beyond the emergency of COVID-19 pandemic, making RM as the true standard of care in this field [31].

AF is a very common arrhythmia and its acute management carries a high burden of workload to EDs and Cardiology Clinics [32]. In view of its epidemiological profile, AF affects subjects in the range of age at highest risk of adverse outcomes if infected by Sars-Cov-2 [33] and the caution in avoiding admissions to hospital may explain the important reduction in acute pharmacological and non-pharmacological treatments applied for AF in emergency setting reported during the study period, as reported in this survey. Since appropriate prescription of oral anticoagulants in patients at risk of stroke is a major determinant of outcome at long term [34-40], it will be necessary in the near future to establish even stricter connections between hospital and out of hospital care, for a re-assessment of patients who presented $\mathrm{AF}$ and these months with regard to clinical evaluation and appropriateness of treatment for ensuring continuity of care. It will also be interesting to assess to what extent untreated or undiscovered AF occurred during the lockdown will result in major consequences, such as syncope, heart failure, stroke/systemic embolism [41-43].

It is surprising that the reduction in activities performed by Arrhythmia services during March-April 2020 also involved ablations performed in emergency setting (including urgent ablation of electrical storm, or of refractory VT or SVT), that require high competence and usually cannot be deferred [44]. The patients' tendency to avoid hospitalization that characterized the peak phase of COVID-19 pandemic could have resulted in an increased amount of cardiovascular deaths occurred at home, but this of difficult to assess now. The implications of the gap of care that the reduction in emergency ablations and electrophysiological interventions implied will require further assessments in the future and should suggest a reorganization of care, with networks able to guarantee these procedures, following an appropriate referral, even in case of national emergencies.

One of the key questions after the outbreak of COVID19 is how to re-organize care in the post-COVID-19 recovery phase and our survey indicated that according to Italian physicians in the field. According to our survey there is absolute need of adopting new organizational models for patient admission in order to minimize the risk of infection. A short-stay hospitalization for patients undergoing elective procedures (i.e. day-case admission or ordinary admission with a single night stay) appears to be a suitable strategy, although up to now it was adopted with substantial heterogeneity, according to administrative reasons and reimbursement policies [45]. According to the majority of respondents, not only device replacements but also ablations for SVTs and elective PM implants could be performed with a short hospital stay, with the advantage to improve efficiency of the system. This perspective will require an increased compliance with prospective registries on electrophysiological procedures [11, 46-49], with our Scientific Association providing specific reports on complication rates and outcomes associated with the different procedures programmed in the field of interventional electrophysiology. This will also be the basis for working with policymakers and regulators for planning audits targeted to verify the quality of care in a virtuous circle where daily practice provides a continuous feedback on health care system performance [50]. This will be the appropriate response to the challenging battle against COVID-19 and will allow to improve the performance of our health care system, with the premise for achieving full confidence of the citizens on the overall appropriateness and safety of our care processes.

\section{Study limitations}

Our survey has some limitations since it was not based on a precise computation of activities and procedure in every specific centre; however, this is a method that allows a 
rapid feedback and was chosen for having a general view of COVID-19 pandemic in Italy at a short time from its onset.

Only 84 out of 372 arrhythmia centres operating in Italy took part in the survey ( $22.6 \%$ of the Italian centres). For this reason, our findings should be interpreted with caution, as they may not accurately reflect the impact of COVID-19 pandemic on the activities of all Italian arrhythmia centres.

Seventeen of the 18 questions of the questionnaire were multiple-choice questions. This type of questionnaire is time-efficient, and responses are easy to code and interpret. On the other hand, the surveys based on multiple-choice questions have some limitations. Respondents are required to choose a response that does not exactly reflect their answer. In addition, the arbitrary design of questionnaires and multiple-choice questions with pre-conceived categories represents a biased and overly simple view of reality.

\section{Conclusions}

The impact of COVID-19 was disrupting on the entire organization of health care, particularly for hospital care, and had a massive impact on the activities related to arrhythmia management and electrophysiology occurred in Italy in March-April 2020. Our survey focused on real-life activities in this field showed that in hospitals with wards specifically dedicated to care of patients with COVID-19 physicians usually involved in the field of arrhythmias and electrophysiology were frequently moved to take care of patients infected by Sars-Cov-2. In this period a reduction of $>50 \%$ in the number of implants of cardiac electronic devices was reported, and involved pacemakers and ICDs, with an important reduction not only on ICD implants for primary prevention of sudden death, but also on ICD implants for secondary prevention. The number of ablation procedures was markedly reduced and the reduction also affected emergency procedures, especially for centres directly involved in the care of COVID-19. In this context, a wider use of RM among patients with implanted devices was achieved, although with a variable extent from centre to centre. It is clear that for the post-COVID-19 recovery phase there is absolute need for adopting new organizational models for patient admission in order to minimize the risk of infection, and a short-stay hospitalization for patients undergoing elective procedures (i.e. day-case admission or ordinary admission with a single night stay) appears to be a suitable strategy. An increased compliance with prospective registries on electrophysiological procedures will allow a continuous monitoring of the type and number of interventions needed in this new phase, with potential differences with regard to historical series, and will also allow a check of centres' performances in specific procedures, with an enormous potential for quality improvement.

\section{Author contributionss}

Conceptualization, GB and RPR.; methodology, GB and PP; software, PP; validation, GB, RPR and GB; formal analysis, $\mathrm{PP}$; investigation, GB; resources, GB; data curation, $\mathrm{GB}$ and $\mathrm{PP}$; writing — original draft preparation, GB, PP; writingreview and editing and visualization, FG, MB, GZ, CL, PN, MA, GB, GBF, ML, AD, RPR and RDP.

Acknowledgements No funding was received for this work.

We acknowledge the AIAC Ricerca Investigators who participated in this survey: Abruzzo: Luise R, Ospedale San Salvatore, L'Aquila; Basilicata: Grieco P, Osp. San Carlo, Potenza; Calabria: Pangallo A, Grande Ospedale Metropolitano di Reggio Calabria, Reggio Calabria; Quirino G, SSC Cardiologia. PO Annunziata, Cosenza; Talarico A, U.O. Cardiologia Azienda Ospedaliera Cosenza, Cosenza; De Bonis S, UOC Cardiologia Castrovillari, ASP Cosenza; Campania: Carbone A, UOC di Cardiologia Osp. Maria SS Addolorata, Eboli (Salerno); De Simone A, Clinica San Michele, Maddaloni (Caserta); D’Onofrio A, AORN Dei Colli Dipartimento di Cardiologia - UOSD di Elettrofisiologia, Studio e Terapia delle Aritmie, Napoli; Nappi F, Rotondi F, AORN Moscati Avellino, Avellino; Stabile G, Clinica Montevergine, Mercogliano (Avellino); Uran C, P.O.S. Giuseppe e Melorio, Santa Maria Capua Vetere (Caserta); Emilia Romagna: Bertini M, Balla C, Azienda Ospedaliero-Universitaria S. Anna, Ferrara; Boggian G, ASL Bologna Ospedale di Bentivoglio, Bentivoglio-Bologna; Carinci V, Barbato G, Ospedale Maggiore - AUSL città di Bologna, Bologna; Corzani A, Sabbatani P, Ospedale Bufalini, Cesena; Erminio M, Azienda Ospedaliero Universitaria Policlinico di Modena, Modena; Imberti JF, Policlinico di Modena, Modena; Malavasi N, Policlinico di Modena, Modena; Pastori P, Ospedale di Fidenza, Fidenza (Parma); Quartieri F, Bottoni N, Aricispedale Santa Maria Nuova, Reggio Emilia; Saporito D, Ospedale Infermi - ASL Romagna, Rimini; Virzì S, Sassone B, Ospedale S.S. Annunziata, Cento (Ferrara); Zardini M, Placci A, AOU Parma, Parma; Ziacchi M, Massaro G, Istituto di Cardiologia, Policlinico S.Orsola Malpighi, Bologna; Lazio: Adamo F, Scaccia A, Spampinato A, Villa Tiberia Hospital, Roma; Biscione F, Cardiologia Ospedale Santo Spirito, Roma; Castro A, Ospedale Pertini, Roma; Cauti F, Rossi P, Aritmologia San Giovanni Calibita Fatebenefratelli Isola Tiberina Roma, Roma; Cinti C, CdC S. Anna Policlinico Città di Pomezia, Pomezia (Roma); Gatto M, Kol A, Ospedale "San Camillo De Lellis", Rieti; Narducci ML, Pelargonio G,, Fondazione Policlinico Universitario Agostino Gemelli IRCCS, Roma ; Patruno N, Ospedale dei Castelli, Ariccia (Roma); Pignalberi C, PO San Filippo Neri, Roma; Ricci RP, Centro cardio-Aritmologico, Roma; Ricciardi D, Policlinico Campus Bio-Medico, Roma; Santini L, Divisione di Cardiologia, Ospedale G.B. Grassi, Roma; Tancredi M, Di Belardino N, Ospedali riuniti Anzio-Nettuno, Anzio (Latina); Liguria: Pentimalli F, Ospedale S Paolo, Savona; Zoni-Berisso M, Ospedale Padre Antero Micone, Genova; Lombardia: Belotti G, UOS Elettrofisiologia, Treviglio (Bergamo); Chieffo E, Ospedale Maggiore di Crema - ASST Crema, Crema (Cremona); Cilloni S, Ospedale Predabissi, Vizzolo Predabissi (Milano); Doni LA, ASST Sette Laghi P.O.U. Ospedale di Circolo e Fondazione Macchi, Varese; Forleo GB, Ospedale Luigi Sacco - ASST FBF Sacco, Milano; Gardini A, Istituto Clinico S. Anna, Brescia; Malaspina D, UOS Elettrofisiologia ed Elettrostimolazione, ASST Santi Paolo e Carlo, PO San Carlo Borromeo, Milano; Mazzone P, Della Bella P, Ospedale San Raffaele di Milano, Milano; Negro R, ASST PAVIA Ospedale civile di Vigevano, Vigevano ; Perego GB, Istituto Auxologico Italiano - Ospedale S. Luca, Milano; Rordorf R, Policlinico S.Matteo, Pavia; Marche: Cipolletta L, Dello Russo A, Azienda Ospedaliera Universitaria Ospedali Riuniti, Ancona; Luzi M, Ospedale Provinciale di Macerata - Area Vasta 3, Macerata; Piemonte: 
Amellone C, Ebrille E, Favro E, Lucciola MT, Cardiologia Ospedale Maria Vittoria, Torino; Devecchi C, P.O. SS. Pietro e Paolo Borgosesia, Vercelli; Rametta F, Devecchi F, Matta M, AO Sant'Andrea, Vercelli; Santagostino M, Dell'Era G, SS Elettrofisiologia AOU Maggiore della Carità, Novara; Puglia: Candida TR, Bonfantino VM, P.O. Di Venere UTIC-Cardiologia, Bari; Gianfrancesco D, Ospedale Bonomo Andria, Andria; Guido A, Azienda Ospedaliera "Cardinale Giovanni Panico", Tricase (Lecce); Pellegrino PL, Cardiologia Universitaria - Policlinico Ospedali Riuniti, Foggia; Pisanò ECL, Ospedale "Vito Fazzi" ASL Lecce, Lecce; Rillo M, Palamà Z, Casa di Cura Villa Verde, Taranto; Sai R, P.O. Sacro Cuore di Gesù, Gallipoli (Lecce); Santobuono VE, Favale S, U.O. Cardiologia Universitaria - A.O.U.C. Policlinico di Bari, Bari; Scicchitano P, P.O. "F. Perinei" Altamura (BA), Altamura (Bari); Sardegna: Nissardi V, Clinica Cardiologica-UTIC - Policlinico "D. Casula", Monserrato - Cagliari; Sicilia: Campisi G, Ospedale Giovanni Paolo II, Ragusa; Sgarito G, ARNAS Ospedale Civico, Palermo; Toscana: Arena G, Cardiologia Massa Carrara, Massa; Casorelli E, Ospedale di Montepulciano, Montepulciano (Siena); Fumagalli S, Unità di Terapia Intensiva Geriatrica (UTIG), Università degli Studi di Firenze e AOU Careggi, Firenze; Giaccardi M, UOS di Cardiologia ed Elettrofisiologia Firenze 1 Azienda sanitaria Firenze, Firenze; Notarstefano P, Nesti M, UOC Cardiologia Arezzo Dipartimento Cardiovascolare e Neurologico ASL Toscana Sud Est, Arezzo; Padeletti M, Ospedale del Mugello, Borgo san Lorenzo (Firenze); Rossi A, Piacenti M, Fondazione Toscana Gabriele Monasterio, Pisa; Trentino-Alto Adige: Del Greco M, Catanzariti D, Ospedale S.M. del Carmine, Rovereto (Trento); Manfrin M, Werner R, Ospedale Regionale di Bolzano, Bolzano; Marini M, Ospedale S. Chiara, Trento; Umbra: Andreoli C, Ospedale S.G. Battista, Foligno (Perugia); Fedeli F, U.O. Cardiologia - Ospedale di Città di Castello, Città di Castello (Perugia); Mazza A, Ospedale S. Maria della Stella, Orvieto (Terni); Pagnotta F, Ridarelli M, PO Gubbio-Gualdo Tadino, Gubbio (Perugia); Veneto: Molon G, IRCCS Ospedale S.Cuore Don Calabria, Negrar (Verona); Rossillo A, Ospedale San Bortolo, Vicenza.

\section{Compliance with ethical standards}

Conflict of interest GB: small speaker fee from Medtronic, Boston, Biotronik, Boehringer Ingelheim and Bayer. PP: small speaker fee from Bayer, Boehringer Ingelheim, Bristol-Myers Squibb, Medtronic. Novartis and personal fees from Proctorship agreement with Abbott, Medtronic, Biotronik, and Boston Scientific. MB: small speaker fee from Boston Scientific, Abbott, Boehringer Ingelheim and Bayer. ML: modest speaker fee from Bayer, Boehringer Ingelheim, Boston Scientific, LivaNova, Medtronic, and Pfizer. RPR: small speaker fees by Boston e Biotronik; advisory board modest fees by Dompé. RDP: lecture fees from Biosense Webster and Biotronik. No conflict of interest reported by the other authors.

Statement of human and animal rights The study procedures were in accordance with the ethical standards of the latest Helsinki declaration.

Informed consent All the participants provided written consent for their participation in this survey at the time of online data collection. Due to the anonymous and voluntary nature of the study, no identifying information about participants was mandatory for inclusion.

\section{References}

1. Moirano G, Richiardi L, Novara C, Maule M (2020) Approaches to daily monitoring of the SARS-CoV-2 outbreak in Northern Italy. Front Public Health 8:222
2. Bedford J, Enria D, Giesecke J, Heymann DL, Ihekweazu C, Kobinger G, Lane HC, Memish Z, Oh MD, Sall AA, Schuchat A, Ungchusak K, Wieler LH, WHO Strategic, and Technical Advisory Group for Infectious Hazards (2020) COVID-19: towards controlling of a pandemic. Lancet 395:1015-1018

3. COVID-19 ITALIA (2020) Data from Italian Civil Protection Department. https://opendatadpc.maps.arcgis.com/apps/opsda shboard/in. Accessed 27 June 2020.

4. Barach P, Fisher SD, Adams MJ, Burstein GR, Brophy PD, Kuo DZ, Lipshultz SE (2020) Disruption of healthcare: Will the COVID pandemic worsen non-COVID outcomes and disease outbreaks? Prog Pediatr Cardiol. 2020;101254. https://doi. org/10.1016/j.ppedcard.2020.101254

5. De Rosa S, Spaccarotella C, Basso C, Calabrò MP, Curcio A, Filardi PP, Mancone M, Mercuro G, Muscoli S, Nodari S, Pedrinelli R, Sinagra G, Indolfi C, Società Italiana di Cardiologia, and the CCU Academy investigators group (2020) Reduction of hospitalizations for myocardial infarction in Italy in the COVID-19 era. Eur Heart J 41:2083-2088

6. Baldi E, Sechi GM, Mare C, Canevari F, Brancaglione A, Primi R, Klersy C, Palo A, Contri E, Ronchi V, Beretta G, Reali F, Parogni P, Facchin F, Rizzi U, Bussi D, Ruggeri S, Oltrona Visconti L, Savastano S; Lombardia CARe researchers (2020) COVID-19 kills at home: the close relationship between the epidemic and the increase of out-of-hospital cardiac arrests. [published online ahead of print, 2020 Jun 20]. Eur Heart J. 2020; ehaa508. https://doi.org/10.1093/eurheartj/ehaa5 08

7. Censimento delle strutture aritmologiche italiane AIAC 2019. https://aiac.it/attivita/censimenti/. Accessed 18 June 2020.

8. Temporelli PL, Tilz RR, Arbelo E, Dagres N, Laroche C, Crijns HJ, Blomstrom-Lundqvist C, Kirchhof P, Lip GYH, Boriani G, Pokushalov E, Nakou E, Brugada J, Tavazzi L (2019) Clinical characteristics of heart failure patients undergoing atrial fibrillation ablation today in Europe. Data from the atrial fibrillation registries of the European Society of Cardiology and the European Heart Rhythm Association. Eur J Heart Fail 21:690-693

9. Maltoni S, Negro A, Camerlingo MD, Pecoraro V, Sassone B, Biffi M, Boriani G (2018) Comparison of cryoballoon and radiofrequency ablation techniques for atrial fibrillation: a meta-analysis. J Cardiovasc Med (Hagerstown) 19:725-738

10. Matta M, Anselmino M, Ferraris F, Scaglione M, Gaita F (2018) Cryoballoon vs radiofrequency contact force ablation for paroxysmal atrial fibrillation: a propensity score analysis. J Cardiovasc Med (Hagerstown) 19:141-147

11. Stabile G, Bertaglia E, Guerra F, Palmisano P, Berisso MZ, Soldati E, Bisignani G, Forleo GB, Zanotto G, Landolina M, De Ponti R, Boriani G, Registro RRP, Ablazioni I, Associazione Italiana di Aritmologia e Cardiostimolazione (2017) 2017 Catheter Ablation Registry of the Italian Association of arrhythmology and cardiac pacing. G Ital Cardiol (Rome) 2019(20):590-592

12. Perlini S, Canevari F, Cortesi S, Sgromo V, Brancaglione A, Contri E, Pettenazza P, Salinaro F, Speciale F, Sechi G, Mare C, Cutti S, Novelli V, Marena C, Muzzi A, Bruno R, Palo A, COVID19 IRCCS San Matteo Pavia Task Force (2020) Emergency Department and Out-of-Hospital Emergency System (112-AREU 118) integrated response to Coronavirus Disease 2019 in a Northern Italy centre. Intern Emerg Med. 2020;15(5):825-833.

13. Bellan M, Gavelli F, Hayden E, Patrucco F, Soddu D, Pedrinelli AR, Cittone MG, Rizzi E, Casciaro GF, Vassia V, Landi R, Menegatti M, Gastaldello ML, Beltrame M, Labella E, Tonello S, Avanzi GC, Pirisi M, Castello LM, Sainaghi PP (2020) Pattern of emergency department referral during the Covid-19 outbreak in Italy. Panminerva Med. https://doi.org/10.23736/S0031 $-0808.20 .04000-8$ (published online ahead of print, 2020 Jun 16) 
14. Toniolo M, Negri F, Antonutti M, Masè M, Facchin D (2020) Unpredictable fall of severe emergent cardiovascular diseases hospital admissions during the COVID-19 pandemic: experience of a single large center in Northern Italy. J Am Heart Assoc. https ://doi.org/10.1161/JAHA.120.017122(Epub ahead of print)

15. Migliore F, Zorzi A, Gregori D, Del Monte A, Falzone PV, Verlato R, Siciliano M, Themistoclakis S, China P, Marchese D, Pasquetto G, Ignatiuk B, Cernetti C, Giacomin E, Calzolari V, Bilato C, Dalla Valle C, Frigo GM, Marinaccio L, Saccà S, Lupo A, Roncon L, Marcantoni L, Tosi A, Turiano G, Folino F, Perazzolo Marra M, Cacciavillani L, Iliceto S, Padua School of Cardiology Network (2020) Urgent pacemaker implantation rates in the veneto region of italy after the COVID-19 outbreak. Circ Arrhythm Electrophysiol 13(6):e008722. https://doi.org/10.1161/CIRCE P.120.008722(Epub 2020 May 20)

16. Ricci RP, Morichelli L, Porfili A, Quarta L, Sassi A (2018) Diagnostic power and healthcare resource consumption of a dedicated workflow algorithm designed to manage thoracic impedance alerts in heart failure patients by remote monitoring. J Cardiovasc Med (Hagerstown) 19:105-112

17. Boriani G (2015) Remote monitoring of cardiac implantable electrical devices in Europe: quo vadis? Europace 17:674-676

18. Palmisano P, Melissano D, Zanotto G, Perego GB, Toselli T, Landolina M, Ricci RP, Italian Association of Arrhythmology, Cardiac Pacing (AIAC) (2020) Change in the use of remote monitoring of cardiac implantable electronic devices in Italian clinical practice over a 5-year period: results of two surveys promoted by the AIAC (Italian Association of Arrhythmology and Cardiac Pacing). J Cardiovasc Med (Hagerstown) 21:305-314

19. Zanotto G, Melissano D, Baccillieri S, Campana A, Caravati F, Maines M, Platania F, Zuccaro L, Landolina M, Berisso MZ, Boriani G, Ricci RP (2020) Intrahospital organizational model of remote monitoring data sharing, for a global management of patients with cardiac implantable electronic devices: a document of the Italian Association of Arrhythmology and Cardiac Pacing. J Cardiovasc Med (Hagerstown) 21:171-181

20. Boriani G, Diemberger I, Martignani C, Biffi M, Valzania C, Bertini M, Domenichini G, Saporito D, Ziacchi M, Branzi A (2008) Telecardiology and remote monitoring of implanted electrical devices: the potential for fresh clinical care perspectives. J Gen Intern Med 23(Suppl 1):73-77

21. Ziacchi M, Palmisano P, Biffi M, Ricci RP, Landolina M, ZoniBerisso M, Occhetta E, Maglia G, Botto G, Padeletti L, Boriani G, Italian Association of Arrhythmology, and Cardiac Pacing (AIAC) (2018) Clinically oriented device programming in bradycardia patients: part 1 (sinus node disease). Proposals from AIAC (Italian Association of Arrhythmology and Cardiac Pacing). J Cardiovasc Med (Hagerstown). 19:161-169

22. Palmisano P, Ziacchi M, Biffi M, Ricci RP, Landolina M, ZoniBerisso M, Occhetta E, Maglia G, Botto G, Padeletti L, Boriani G, Italian Association of Arrhythmology, and Cardiac Pacing (AIAC) (2018) Clinically oriented device programming in bradycardia patients: part 2 (atrioventricular blocks and neurally mediated syncope). Proposals from AIAC (Italian Association of Arrhythmology and Cardiac Pacing). J Cardiovasc Med (Hagerstown) 19:170-180

23. Russo V, Nigro G, D'Onofrio A (2020) COVID-19 and cardiac implantable electronic device remote monitoring: crocodile tears or new opportunity? Expert Rev Med Devices 17:471-472

24. Slotwiner D, Varma N, Akar JG, Annas G, Beardsall M, Fogel RI, Galizio NO, Glotzer TV, Leahy RA, Love CJ, McLean RC, Mittal S, Morichelli L, Patton KK, Raitt MH, Ricci RP, Rickard J, Schoenfeld MH, Serwer GA, Shea J, Varosy P, Verma A, Yu CM (2015) HRS Expert Consensus Statement on remote interrogation and monitoring for cardiovascular implantable electronic devices. Heart Rhythm 12:e69-e100
25. Boriani G, Da Costa A, Ricci RP, Quesada A, Favale S, Iacopino S, Romeo F, Risi A, di Mangoni S, Stefano L, Navarro X, Biffi M, Santini M, Burri H, MORE-CARE Investigators (2013) The MOnitoring Resynchronization dEvices and CARdiac patiEnts (MORE-CARE) randomized controlled trial: phase 1 results on dynamics of early intervention with remote monitoring. J Med Internet Res 15:e167

26. Santini L, D'Onofrio A, Dello Russo A, Calò L, Pecora D, Favale S, Petracci B, Molon G, Bianchi V, De Ruvo E, Ammirati F, La Greca C, Campari M, Valsecchi S, Capucci A (2020) Prospective evaluation of the multisensor HeartLogic algorithm for heart failure monitoring. Clin Cardiol. https://doi.org/10.1002/clc.23366

27. Artico J, Zecchin M, Zorzin Fantasia A, Skerl G, Ortis B, Franco S, Albani S, Barbati G, Cristallini J, Cannata' A, Sinagra G (2019) Long-term patient satisfaction with implanted device remote monitoring: a comparison among different systems. J Cardiovasc Med (Hagerstown) 20(8):542-550

28. de Moraes ERFL, Cirenza C, Lopes RD, Carvalho AC, Guimaraes PO, Rodrigues AAE, de Paola AAV (2019) Prevalence of atrial fibrillation and stroke risk assessment based on telemedicine screening tools in a primary healthcare setting. Eur J Intern Med 67:36-41

29. Austin JM, Kachalia A (2020) The state of health care quality measurement in the era of COVID-19: the importance of doing better. JAMA. https://doi.org/10.1001/jama.2020.11461

30. Padula MS, D'Ambrosio GG, Tocci M, D'Amico R, Banchelli F, Angeli L, Scarpa M, Capelli O, Cricelli C, Boriani G (2019) Home care for heart failure: can caregiver education prevent hospital admissions? A randomized trial in primary care. J Cardiovasc Med (Hagerstown) 20:30-38

31. Varma N, Marrouche NF, Aguinaga L, Albert CM, Arbelo E, Choi JI, Chung MK, Conte G, Dagher L, Epstein LM, Ghanbari H, Han JK, Heidbuchel H, Huang H, Lakkireddy DR, Ngarmukos T, Russo AM, Saad EB, Saenz Morales LC, Sandau KE, Sridhar ARM, Stecker EC, Varosy PD. HRS/EHRA/ APHRS/LAHRS/ACC/AHA worldwide practice update for telehealth and arrhythmia monitoring during and after a pandemic. [published online ahead of print, 2020 Jun 11]. Heart Rhythm. 2020;S1547-5271(20)30552-X. https://doi.org/10.1016/j.hrthm .2020 .06 .010

32. Gulizia MM, Cemin R, Colivicchi F, De Luca L, Di Lenarda A Boriani G, Di Pasquale G, Nardi F, Scherillo M, Lucci D, Fabbri G, Maggioni AP, BLITZ-AF Investigators (2019) Management of atrial fibrillation in the emergency room and in the cardiology ward: the BLITZ AF study. Europace 21(2):230-238. https://doi. org/10.1093/europace/euy166

33. Boriani G, Diemberger I, Martignani C, Biffi M, Branzi A (2006) The epidemiological burden of atrial fibrillation: a challenge for clinicians and health care systems. Eur Heart J 27:893-894

34. Marietta M, Banchelli F, Pavesi P, Manotti C, Quintavalla R, Sinigaglia T, Guazzaloca G, Pattacini C, Urbinati S, Malavasi VL, Boriani G, Voci C, D’Amico R, Magrini N (2019) Direct oral anticoagulants vs non-vitamin $\mathrm{K}$ antagonist in atrial fibrillation: a prospective, propensity score adjusted cohort study. Eur J Intern Med 62:9-16

35. Boriani G, Proietti M, Laroche C, Diemberger I, Popescu MI, Riahi S, Shantsila A, Dan GA, Tavazzi L, Maggioni AP, Lip GYH, EORP-AF Pilot General Registry Investigators (2018) Changes to oral anticoagulant therapy and risk of death over a 3-year followup of a contemporary cohort of European patients with atrial fibrillation final report of the EURObservational Research Programme on Atrial Fibrillation (EORP-AF) pilot general registry. Int J Cardiol 271:68-74

36. Proietti M, Laroche C, Nieuwlaat R, Crijns HJGM, Maggioni AP, Lane DA, Boriani G, Lip GYH, EORP-AF General Pilot Registry; Euro Heart Survey on AF Investigators (2018) Increased burden of 
comorbidities and risk of cardiovascular death in atrial fibrillation patients in Europe over ten years: a comparison between EORPAF pilot and EHS-AF registries. Eur J Intern Med 55:28-34

37. Diemberger I, Fantecchi E, Reggiani MLB, Martignani C, Angeletti A, Massaro G, Ziacchi M, Biffi M, Lip GYH, Boriani G (2018) Atrial fibrillation and prediction of mortality by conventional clinical score systems according to the setting of care. Int $\mathbf{J}$ Cardiol 261:73-77

38. Vitolo M, Proietti M, Harrison S, Lane DA, Potpara TS, Boriani G, Lip GYH (2020) The Euro Heart Survey and EURObservational Research Programme (EORP) in atrial fibrillation registries: contribution to epidemiology, clinical management and therapy of atrial fibrillation patients over the last 20 years. Intern Emerg Med. https://doi.org/10.1007/s11739-020-02405-0

39. Proietti M, Marzona I, Vannini T, Tettamanti M, Fortino I, Merlino L, Basili S, Mannucci PM, Boriani G, Lip GYH, Roncaglioni MC, Nobili A (2019) Long-term relationship between atrial fibrillation, multimorbidity and oral anticoagulant drug use. Mayo Clin Proc 94:2427-2436

40. Boriani G, Proietti M, Laroche C, Fauchier L, Marin F, Nabauer M, Potpara T, Dan GA, Kalarus Z, Tavazzi L, Maggioni AP, Lip GYH (2019) Association between antithrombotic treatment and outcomes at 1-year follow-up in patients with atrial fibrillation: the EORP-AF General Long-Term Registry. Europace 21:1013-1022

41. Keller K, Hobohm L, Münzel T, Ostad MA (2019) Syncope in the German Nationwide inpatient sample-syncope in atrial fibrillation/flutter is related to pulmonary embolism and is accompanied by higher in-hospital mortality. Eur J Intern Med 62:29-36

42. De Simone V, Zanotto G, Guarisse P, Venturato A, Cassinadri E, Bassi M, Bozzolin M, Tondelli S, Giacopelli D, Morando G (2019) Effects of remote monitoring of cardiac implantable electronic devices after stroke or transient ischemic attack. J Cardiovasc Med (Hagerstown) 20(8):551-556

43. Mazza A, Bendini MG, Valsecchi S, Lovecchio M, Leggio M, De Cristofaro R, Boriani G (2019) Occurrence of atrial fibrillation in pacemaker patients and its association with sleep apnea and heart rate variability. Eur J Intern Med 68:13-17

44. Vergara P, Casella M, Barbato G, De Ruvo E, Grandinetti G, Notarstefano P, Tola G, Calvi V, Santini L, Nissardi V, Nonis A, Ricci RP, Boriani G, Tondo C, Della BP (2019) Nationwide survey on the current practice of ventricular tachycardia ablation. J Cardiovasc Med (Hagerstown) 20(9):597-605

45. Palmisano P, Ziacchi M, Belotti G, Rapacciuolo A, Santini L, Stabile G, Berisso MZ, De Ponti R, Landolina M, Ricci RP,
Boriani G, for AIAC Ricerca Investigators (2019) Clinical and organizational management of cardiac implantable electronic device replacements: an Italian Survey promoted by AIAC (Italian Association of Arrhythmology and Cardiac Pacing). J Cardiovasc Med (Hagerstown) 20:531-541

46. Proclemer A, Zecchin M, D'Onofrio A, Boriani G, Ricci RP, Rebellato L, Ghidina M, Bianco G, Bernardelli E, Miconi A, Zorzin AF, Gregori D, Registro Italiano Pacemaker e Defibrillatori-Bollettino Periodico; Associazione Italiana di Aritmologia e Cardiostimolazione (2018) The pacemaker and implantable cardioverter-defibrillator registry of the Italian Association of Arrhythmology and Cardiac Pacing-annual report 2018. G Ital Cardiol (Rome) 2020(21):157-169

47. Poli S, Boriani G, Zecchin M, Facchin D, Gasparini M, Landolina M, Ricci RP, Lanera C, Gregori D, Proclemer A (2019) Favorable trend of implantable cardioverter-defibrillator service life in a large single-nation population: insights from 10-year analysis of the Italian Implantable Cardioverter-Defibrillator Registry. J Am Heart Assoc 8(15):e012759. https://doi.org/10.1161/ JAHA.119.012759

48. Malavasi VL, De Marco G, Imberti JF, Placentino F, Vitolo M, Mazzeo E, Cicoria G, Casali E, Turco V, Lohr F, Boriani G (2019) Radiotherapy-induced malfunctions of cardiac implantable electronic devices in cancer patients. Intern Emerg Med. https://doi. org/10.1007/s11739-019-02240-y(Epub ahead of print)

49. Gullón A, Formiga F, Díez-Manglano J, Mostaza JM, Cepeda JM, Pose A, Castiella J, Suárez-Fernández C, NONAVASC study group Vascular Risk Group of the Spanish Society of Internal Medicine (2019) Influence of frailty on anticoagulant prescription and clinical outcomes after 1-year follow-up in hospitalised older patients with atrial fibrillation. Intern Emerg Med 14(1):59-69

50. Boriani G, Maniadakis N, Auricchio A, Müller-Riemenschneider F, Fattore G, Leyva F, Mantovani L, Siebert M, Willich SN, Vardas P, Kirchhof P (2013) Health technology assessment in interventional electrophysiology and device therapy: a position paper of the European Heart Rhythm Association. Eur Heart J 34:1869-1874

Publisher's Note Springer Nature remains neutral with regard to jurisdictional claims in published maps and institutional affiliations.

\section{Affiliations}

\section{Giuseppe Boriani ${ }^{1}(\mathbb{1})$ Pietro Palmisano ${ }^{2}$. Federico Guerra ${ }^{3} \cdot$ Matteo Bertini $^{4}$ - Gabriele Zanotto ${ }^{5}$. Carlo Lavalle ${ }^{6}$. Pasquale Notarstefano ${ }^{7} \cdot$ Michele Accogli $^{2} \cdot$ Giovanni Bisignani $^{8}$. Giovanni Battista Forleo ${ }^{9} \cdot$ Maurizio Landolina ${ }^{10}$. Antonio D'Onofrio ${ }^{11} \cdot$ Renato Ricci $^{12} \cdot$ Roberto De Ponti $^{13}$ on behalf of AIAC Ricerca Network Investigators}

1 Cardiology Division, Department of Biomedical, Metabolic and Neural Sciences, University of Modena and Reggio Emilia, Policlinico Di Modena, Via del Pozzo 71, 41121 Modena, Italy

2 Cardiology Unit, "Card. G. Panico” Hospital, Tricase, Italy

3 Cardiology and Arrhythmology Clinic, Marche Polytechnic University, University Hospital Umberto I-Lancisi-Salesi, Ancona, Italy

4 Cardiology Unit, Azienda Ospedaliero-Universitaria Di Ferrara "Arcispedale S. Anna", Cona, Ferrara, Italy
5 Department of Cardiology, Mater Salutis Hospital, Legnago, Verona, Italy

6 Department of Cardiology, Policlinico Universitario Umberto I, Roma, Italy

7 Cardiovascular Department, San Donato Hospital, Arezzo, Italy

8 Cardiology Division, Castrovillari Hospital, ASP Cosenza, Castrovillari, Italy

9 Ospedale Luigi Sacco, Milano, Italy 
10 Cardiology Department, Ospedale Maggiore Di Crema, Crema, CR, Italy

11 Departmental Unit of Electrophysiology, Evaluation and Treatment of Arrhythmias, Monaldi Hospital, Naples, Italy
12 Centro Cardio-Aritmologico, Roma, Italy

13 Department of Heart and Vessels, Ospedale Di Circolo-University of Insubria, Varese, Italy 